prolonged imprisonment, the need to protect the public, and the possibility that reduction of sexual drive may facilitate psychotherapy. But clearly the nature of the treatment must be carefully explained to the patient and his voluntary consent to it obtained. It would also be preferable at this stage for the operation to be confined to individuals whose motivation is uninfluenced by legal or other forms of duress.

At present hypothalamotomy is unlikely to be of more than very limited application in the treatment of sexual deviations. It would seem that the persons for whom it might be considered are those suffering from uncontrollable sexual drives directed towards children of either sex. If after careful assessment surgery is advised, it should be carried out in a specialist centre and followed by a detailed and systematic evaluation of the immediate and late effects of the operation on psychological, sexual, and physiological functioning. It is essential that, despite the difficulties, a rigorous controlled assessment of the effects of the operation should be made before clinical development beyond the experimental stage is considered.

\section{Mechanisms of Toxicity}

The effects of poisons on man and animals are interesting and important for several reasons. Investigations into the disruptive effects of poisons carried out under controlled conditions have provided valuable information about pathways of intermediary metabolism and about factors controlling intracellular organization and the interrelationship of different metabolic pathways. In some instances the observation of similarities between the effects of toxic agents-for example, on the nervous system-has suggested the existence of structural similarities between a compound of unknown structure and one that has been fully characterized. This has indicated further lines of research on the unknown compound. However, a structural relationship as such between the two agents does not necessarily follow from such physiological and pharmacological observations. At the molecular level, several poisons have been used to investigate the structure of active centres of enzymes.

Clinically, the rational approach to the specific treatment of the growing number of patients who have poisoned themselves accidentally, or who are classified as suffering from self-poisoning (perhaps owing to a need to draw attention to a critical situation without necessarily intending to end life), or who have poisored themselves with deliberate suicidal intent must await the provision of more precise information about the mechanism of action of an ever widening range of toxic agents. Supportive therapy, both medical and psychiatric, will nevertheless retain an essential place in the management of these patients, and the development of methods for rapidly identifying poisons and their metabolites, as well as the introduction of specific antidotes, will serve only as adjuncts to the medical regimen.

For many reasons, therefore, research into mechanisms of toxicity is important, and the recent issue of the British Medical Bulletin ${ }^{1}$ provides a valuable and timely reminder of this fact. Dedicated to Sir Rudolph Peters, one of the first actively to explore the idea of lethal synthesis and the nature

\footnotetext{
1 British Medical Bulletin, 25, No. 3, September 1969. Mechanisms of Toxicity (W. N. Aldridge, scientific editor). $£ 2$.
}

of the biochemical lesion underlying the toxic action of various compounds, this issue of the Bulletin contains a wideranging series of authoritative short review articles. They include accounts of diet and toxicity and of specific groups of toxic compounds-for example, organophosphates, carbamates, nitroso derivatives, and bipyridyls. Other articles review the metabolism of these substances or their effects on specific regions of the body such as the central nervous system or the liver. Attention is paid throughout to evidence which helps to explain the underlying mechanisms of action. Clearly the coverage cannot be comprehensive, but sufficient is said to introduce the non-expert reader to the importance of toxic agents, and the high quality of the articles should succeed in stimulating further interest in this field.

\section{Cyclone over Cyclamates}

Last week the Minister of Agriculture announced a Government decision that cyclamates would be banned in food from 1 January. Many may ask how a food additive which was for years considered to be safe within prescribed limits for human consumption should suddenly be condemned here and abroad. It must be emphasized that the condemnation does not rest on any evidence that cyclamates can cause cancer in man. If any article should have been withdrawn from sale to the public on those grounds the cigarette would have been.

At present there is no evidence that the consumption of cyclamates can injure even people who consume them in the largest quantities. But it is entirely reasonable that tests on experimental animals should be used as a basis for assessing the possible risks to man. Indeed, thorough animal experiments must be carried out on food additives, for their consumption by man is far too haphazard to allow a clear estimate to be formed of any risk they may carry. Experiments in the United States have shown that a proportion of rats fed on a diet containing cyclamates developed malignant growths in the urinary bladder when examined at the end of their life span. The average daily dose consumed by these animals was $2.5 \mathrm{~g}$. per $\mathrm{kg}$. body weight, and to receive such a dose in Britain an adult would need to drink every day 1,000 glasses of one of the cyclamate-containing softdrinks. ${ }^{1}$ Apparently the law in the U.S.A. gave the authorities no choice but to condemn the use of cyclamates in human food as soon as experts had agreed that, given to rats in these large amounts, they could produce cancer of the bladder in some of the animals.

It is perfectly understandable that public health authorities in other countries, including our own, should follow the recommendation of the U.S. Food and Drugs Administration, for they have no evidence to contradict the experimental findings. But there is no reason to condemn anyone for failing to ban the use of cyclamates hitherto, and it is reasonable to assume that no human being has incurred a risk at all commensurate with that of the experimental rats. What would seem to be desirable now is a series of carefully controlled animal experiments on saccharine. Though no harmful effect has come to light in some 50 years of human consumption, and there is no reason to suppose it has any, it is being taken in considerable quantities, which are likely to increase with the withdrawal of cyclamates. 